\title{
State-specific cigarette use rates among service members and veterans, United States, 2017
}

\author{
Justin T. McDaniel', Robert Klesges ${ }^{2}$
}

\begin{abstract}
INTRODUCTION Little is known about the geographical distribution of cigarette use among military service members and veterans. In this study, we estimated statespecific rates of current cigarette use for service members and veterans and compared these to the current cigarette use rates of civilians.

METHODS We used data from the 2017 Behavioral Risk Factor Surveillance System to generate survey-weighted percentages with $95 \%$ confidence intervals of current cigarette use among service members and veterans (SMVs) and civilians. Respondents $(n=450016)$ were classified as an SMV if they answered in the affirmative to the following question: 'Have you ever served on active duty in the United States Armed Forces, either in the regular military or in a National Guard or military reserve unit?'. Current cigarette users were persons who reported having smoked 100 cigarettes in their lifetime and smoked 'some days' or 'every day' at the administration of the survey.

RESULTS Nationally, 17.3\% (95\% CI: 16.6-18.0) of SMVs reported current cigarette use, while $16.2 \%$ (95\% CI: $16.0-16.5$ ) of civilians reported current cigarette use. By state, current cigarette use rates ranged from 10.0\% in Utah (95\% CI: 7.5-12.5) to $23.7 \%$ in Indiana (95\% CI: 20.9-26.5) among service members and veterans, and from $8.8 \%$ in Utah (95\% CI: 8.0-9.6) to $27.0 \%$ in West Virginia (95\% CI: 25.3-28.6) among civilians.

CONCLUSIONS Resources and interventions directed at cigarette smoking cessation should consider military status and geography when recruiting participants.
\end{abstract}

\section{AFFILIATION \\ 1 Department of Public Health and Recreation Professions, Southern Illinois University, Carbondale, United States \\ 2 Center for Addiction and Prevention Research, Department of Public Health Sciences, University of Virginia, Charlottesville, United States \\ CORRESPONDENCE TO Justin T. McDaniel. Department of Public Health and Recreation Professions, Southern Illinois University, 475 Clocktower Drive, MC 4632, Carbondale, IL 62901, United States. \\ E-mail: jtmcd@siu.edu}

\section{KEYWORDS}

military, veterans, cigarettes, tobacco, civilians, geography

Received: 7 July 2019

Revised: 5 August 2019

Accepted: 6 August 2019

\section{INTRODUCTION}

Nationally representative studies in the United States have shown that cigarette use rates are higher among service members and veterans (SMVs) than for civilians ${ }^{1}$. However, no study has investigated the state-level distribution of cigarette use among SMVs and civilians. Because the United States Veterans Health Administration spends approximately $\$ 2$ billion per year in healthcare directly attributable to smoking ${ }^{2}$, there is a need for the identification of high cigarette use regions and subsequent development of geographically targeted programming. As such, the aim of the present study was to estimate the rate of current cigarette use among SMVs and civilians, separately, for each state in the United States.

\section{METHODS}

State-specific estimates of self-reported current cigarette use among SMVs and civilians were calculated using data from the 2017 Behavioral Risk Factor Surveillance System (BRFSS) ${ }^{3}$. The BRFSS is a nationally representative telephone-based survey conducted annually in the United States by the Centers for Disease Control and Prevention. Information is collected from residents in all 50 states regarding their health behaviors, use of preventive health services, and chronic health conditions.

Respondents $(n=450016)$ in this study were 
classified as an SMV if they answered in the affirmative to the following question: 'Have you ever served on active duty in the United States Armed Forces, either in the regular military or in a National Guard or military reserve unit?'. Responses were: yes $=57868$, no $=391408$, don't know $=120$, refused $=609$, and missing $=11$. Respondents who answered 'don't know' or 'refused' were excluded from the analysis.

Two questions were used to determine current cigarette use: a) have you smoked at least 100 cigarettes in your entire life; and b) do you now smoke cigarettes every day, some days, or not at all?. Current cigarette users were persons who reported having smoked 100 cigarettes and smoked 'some days' or 'every day' at the administration of the survey. Respondents who answered 'don't know/ refused' to the first smoking question were excluded from the analysis. In total, 15934 respondents were excluded because of missing data on the 'current cigarette user' variable, thus the final sample size was 433342.

National and state-specific estimates of and 95\% confidence intervals for current cigarette use were adjusted for the BRFSS complex survey design. Sampling weights accounted for survey non-coverage, non-response, and telephone-only households ${ }^{4}$. Estimates for states with unweighted sample sizes of SMVs or civilians $<50$ or relative standard errors (RSE) $>30 \%$ were suppressed ${ }^{5}$. For each state, we also regressed - in logistic regression models - current cigarette use $(0=$ no, $1=$ yes $)$ on SMV status $(0=$ no, $1=$ yes $)$ in order to obtain a $\mathrm{p}$-value for differences in smoking prevalence between civilians and SMVs.

\section{RESULTS}

Among 55868 (weighted $n=25285001$ ) SMVs in the United States, 8313 (weighted $\mathrm{n}=4362402$ ) reported current use of cigarettes (17.3\%, 95\% CI: 16.6-18.0). Among 375080 (weighted $n=217077890$ ) civilians in the United States, 55071 (weighted $n=35211188$ ) reported current use of cigarettes $(16.2 \%, 95 \%$ CI: 16.0-16.5). The difference in current cigarette smoking rates at the national level between SMVs and civilians was statistically significant at an alpha level of 0.05 .

By state (Table 1), current cigarette use rates ranged from $10.0 \%$ (Utah) to $23.7 \%$ (Indiana) among SMVs, and from $8.8 \%$ (Utah) to $27.0 \%$ (West Virginia) among civilians. Based on an alpha level of 0.05, results showed that 4 states/districts (i.e. Arizona, California, District of Columbia, and Idaho) exhibited higher current cigarette use rates among SMVs than among civilians, while 3 states (i.e. Delaware, Florida, and West Virginia) exhibited higher current cigarette use rates among civilians than among SMVs. Differences in current cigarette smoking rates between civilians and SMVs were not significant in all other states.

Table 1. State-specific rates of current cigarette use among adults with no military experience and adult service members and veterans, based on data from the Behavioral Risk Factor Surveillance System (BRFSS), United States, 2017

\begin{tabular}{|c|c|c|c|c|c|c|c|c|c|}
\hline & \multirow[b]{3}{*}{$n^{*}$} & \multicolumn{4}{|c|}{ Vo Vilitary Experience } & \multicolumn{4}{|c|}{ Service Vember or Veteran } \\
\hline & & \multicolumn{4}{|c|}{$95 \% \mathrm{CI}$} & \multicolumn{4}{|c|}{$95^{\circ} \mathrm{CI}$} \\
\hline & & $\%$ & Low & Iligh & $n^{*}$ & $\%$ & Low & Iligh & $p^{s}$ \\
\hline United States & 55071 & 16.20 & 16.00 & 16.50 & 8313 & 17.30 & 16.60 & 18.00 & 0.01 \\
\hline \multicolumn{10}{|l|}{ State } \\
\hline Alabama & 5569 & 21.11 & 19.57 & 22.65 & 898 & 19.96 & 16.27 & 23.64 & 0.58 \\
\hline Alaska & 2534 & 20.89 & 17.97 & 23.82 & 547 & 21.66 & 15.22 & 28.10 & 0.83 \\
\hline Arizona & 12404 & 15.23 & 14.36 & 16.10 & 2340 & 17.98 & 15.90 & 20.05 & 0.01 \\
\hline Arkansas & 4362 & 22.71 & 20.24 & 25.18 & 730 & 18.48 & 13.33 & 23.63 & 0.17 \\
\hline California & 7844 & 11.02 & 10.02 & 12.02 & 859 & 14.36 & 11.03 & 17.68 & 0.04 \\
\hline Colorado & 7775 & 14.65 & 13.63 & 15.68 & 1141 & 14.64 & 12.07 & 17.20 & 0.99 \\
\hline Connecticut & 9019 & 12.84 & 11.79 & 13.90 & 1040 & 11.28 & 8.33 & 14.24 & 0.35 \\
\hline Delaware & 3360 & 17.67 & 15.81 & 19.54 & 594 & 12.66 & 8.84 & 16.48 & 0.04 \\
\hline DC & 3410 & 13.95 & 12.40 & 15.50 & 335 & 19.67 & 14.46 & 24.89 & 0.02 \\
\hline
\end{tabular}


Table 1. Continued

\begin{tabular}{|c|c|c|c|c|c|c|c|c|c|}
\hline & \multicolumn{5}{|c|}{ Vo Vilitary Experience } & \multicolumn{4}{|c|}{ Service Vember or Veteran } \\
\hline & \multirow[b]{2}{*}{$n^{*}$} & \multicolumn{4}{|c|}{$95 \% \mathrm{CI}$} & \multicolumn{4}{|c|}{$95^{\circ} \% \mathrm{CI}$} \\
\hline & & $\%$ & Low & Iligh & $n^{*}$ & $\%$ & Low & Iligh & $p^{\varsigma}$ \\
\hline Florida & 17838 & 16.54 & 15.26 & 17.83 & 3170 & 13.11 & 10.58 & 15.64 & 0.03 \\
\hline Georgia & 4887 & 17.14 & 15.70 & 18.58 & 830 & 19.41 & 15.83 & 22.99 & 0.23 \\
\hline Hawaii & 6352 & 12.69 & 11.53 & 13.84 & 1067 & 13.41 & 10.34 & 16.48 & 0.66 \\
\hline Idaho & 4125 & 13.78 & 12.25 & 15.30 & 618 & 18.50 & 13.93 & 23.07 & 0.04 \\
\hline Illinois & 4794 & 15.49 & 14.09 & 16.89 & 551 & 15.11 & 11.37 & 18.84 & 0.85 \\
\hline Indiana & 11624 & 21.57 & 20.50 & 22.64 & 1626 & 23.70 & 20.90 & 26.50 & 0.15 \\
\hline lowa & 6543 & 16.84 & 15.72 & 17.96 & 888 & 18.93 & 15.75 & 22.11 & 0.21 \\
\hline Kansas & 18018 & 17.30 & 16.56 & 18.04 & 2654 & 17.87 & 15.99 & 19.74 & 0.58 \\
\hline Kentucky & 7369 & 24.96 & 23.27 & 26.65 & 970 & 22.07 & 18.07 & 26.08 & 0.21 \\
\hline Louisiana & 3983 & 23.41 & 21.62 & 25.20 & 547 & 19.73 & 15.28 & 24.17 & 0.15 \\
\hline Maine & 8020 & 17.13 & 15.75 & 18.51 & 1297 & 18.11 & 14.61 & 21.62 & 0.60 \\
\hline Maryland & 11093 & 13.66 & 12.59 & 14.73 & 1832 & 15.38 & 12.34 & 18.42 & 0.28 \\
\hline Massachusetts & 5962 & 13.40 & 11.98 & 14.81 & 696 & 17.27 & 11.96 & 22.58 & 0.13 \\
\hline Michigan & 9347 & 19.06 & 17.98 & 20.14 & 1139 & 21.17 & 18.06 & 24.27 & 0.20 \\
\hline Minnesota & 14451 & 14.42 & 13.63 & 15.20 & 1951 & 15.31 & 13.18 & 17.44 & 0.43 \\
\hline Mississippi & 4159 & 22.70 & 20.71 & 24.68 & 648 & 18.42 & 14.22 & 22.62 & 0.09 \\
\hline Missouri & 6380 & 20.89 & 19.42 & 22.36 & 987 & 19.74 & 15.87 & 23.61 & 0.59 \\
\hline Montana & 4915 & 17.37 & 15.84 & 18.90 & 865 & 15.75 & 12.24 & 19.27 & 0.42 \\
\hline Nebraska & 13013 & 15.67 & 14.64 & 16.69 & 1828 & 13.06 & 10.76 & 15.37 & 0.06 \\
\hline Nevada & 3077 & 16.76 & 14.74 & 18.79 & 563 & 22.77 & 16.18 & 29.36 & 0.06 \\
\hline New Hampshire & 4706 & 16.03 & 14.31 & 17.76 & 787 & 12.63 & 8.60 & 16.65 & 0.16 \\
\hline New Jersey & 10110 & 13.56 & 12.39 & 14.72 & 1092 & 16.46 & 12.23 & 20.68 & 0.17 \\
\hline New Mexico & 5398 & 17.84 & 16.30 & 19.37 & 850 & 14.85 & 11.60 & 18.10 & 0.12 \\
\hline New York & 10524 & 13.89 & 12.95 & 14.83 & 1016 & 16.63 & 12.95 & 20.31 & 0.13 \\
\hline North Carolina & 4044 & 17.18 & 15.58 & 18.78 & 693 & 17.04 & 13.50 & 20.57 & 0.94 \\
\hline North Dakota & 5838 & 17.86 & 16.46 & 19.26 & 901 & 21.37 & 17.64 & 25.11 & 0.07 \\
\hline Ohio & 10401 & 21.25 & 19.99 & 22.52 & 1465 & 20.36 & 17.29 & 23.42 & 0.60 \\
\hline Oklahoma & 5393 & 20.23 & 18.70 & 21.75 & 972 & 19.74 & 16.43 & 23.05 & 0.79 \\
\hline Oregon & 4453 & 16.28 & 14.93 & 17.63 & 663 & 14.61 & 11.34 & 17.89 & 0.37 \\
\hline Pennsylvania & 5626 & 18.67 & 17.29 & 20.04 & 721 & 19.66 & 15.86 & 23.45 & 0.63 \\
\hline Rhode Island & 4664 & 15.21 & 13.55 & 16.86 & 715 & 12.64 & 9.27 & 16.01 & 0.20 \\
\hline South Carolina & 9225 & 18.93 & 17.73 & 20.13 & 1654 & 17.60 & 15.04 & 20.16 & 0.36 \\
\hline South Dakota & 5869 & 19.08 & 16.98 & 21.17 & 964 & 20.69 & 15.64 & 25.73 & 0.56 \\
\hline Tennessee & 4826 & 22.68 & 20.92 & 24.45 & 735 & 22.04 & 17.80 & 26.28 & 0.79 \\
\hline Texas & 10120 & 15.42 & 13.89 & 16.96 & 1556 & 18.27 & 13.77 & 22.76 & 0.22 \\
\hline Utah & 8961 & 8.79 & 8.01 & 9.56 & 996 & 10.00 & 7.48 & 12.51 & 0.35 \\
\hline Vermont & 5484 & 15.68 & 14.28 & 17.08 & 722 & 17.10 & 12.56 & 21.64 & 0.55 \\
\hline Virginia & 7727 & 16.15 & 14.95 & 17.34 & 1546 & 17.88 & 15.10 & 20.66 & 0.25 \\
\hline Washington & 10873 & 13.52 & 12.63 & 14.42 & 1888 & 13.54 & 11.47 & 15.61 & 0.99 \\
\hline West Virginia & 4650 & 26.95 & 25.27 & 28.63 & 717 & 19.07 & 15.60 & 22.54 & $<0.001$ \\
\hline Wisconsin & 4883 & 16.03 & 14.58 & 17.47 & 651 & 16.23 & 12.21 & 20.25 & 0.93 \\
\hline Wyoming & 3707 & 18.75 & 17.05 & 20.45 & 654 & 18.63 & 14.78 & 22.48 & 0.96 \\
\hline
\end{tabular}

* Unweighted sample size. Cl: confidence interval. + Weighted \%; all relative standard errors (RSE) for percentages $<30 \%$. § p-value from z-statistic for SMV coefficient in logistic regression model. 


\section{DISCUSSION}

Nationally aggregated data from the 2017 BRFSS indicated that current cigarette smoking rates were $6.4 \%$ higher among SMVs than civilians. However, significant state-level variation was observed in cigarette use rates in these two populations, with rates as high as $23.7 \%$ among SMVs (Indiana) and $27 . \%$ among civilians (West Virginia).

While previous studies have concluded that SMVs have higher cigarette use rates at the national level, these studies did not examine cigarette use rates at finer geographical levels (i.e. the state level). The results of this study could inform state-based efforts to prevent and end cigarette use, especially among SMVs. Specifically, one possible policy-related intervention to eliminate cigarette smoking among active duty military service members would include a comprehensive ban on tobacco use at all stages of military service. A current military policy prohibits tobacco use during basic training; however, a ban on tobacco use throughout the entire length of military service would be more effective ${ }^{6}$.

Other state-level policy interventions to curb cigarette use among SMVs - veterans in particular - could include higher excise taxes on cigarettes. Yet another state-level policy intervention in high cigarette use states could center on the development of tailored messaging strategies for SMVs via state quitlines. Although the United States Department of Veterans Affairs (VA) has a quitline for veterans specifically, non-VA quitlines could incorporate veteran specific response strategies, as not all veterans use VA-related resources. Given that many state quitlines maintain specialized materials for certain populations, such as sexual minorities, individuals with low literacy levels, pregnant women, senior citizens, and certain racial/ethnic minorities ${ }^{7}$, incorporation of SMV specific materials could result in more effective cessation efforts for SMVs who use non-VA state quitlines.

Finally, cigarette smoking cessation among military veterans may be aided by veteran service organizations, such as The Mission Continues and Team Red, White, and Blue. These veteran service organizations exist to help veterans reintegrate into civilian society by providing social connection opportunities and encouraging a healthy lifestyle, among other things, following military service ${ }^{8,9}$.
These veteran service organizations maintain chapters in many states in the United States. Chapters operating in states with high SMV cigarette use rates may consider implementing cigarette smoking cessation campaigns to curb the excessive smoking rate.

\section{Strengths and limitations}

Strengths of this study include the large, nationally representative, geo-coded sample as well as the provision of a dataset (Table 1) that could be used by healthcare providers and legislators responsive to the needs of SMVs. Limitations of this study include the lack of temporal analysis and the use of self-reported data.

\section{CONCLUSIONS}

This is the first study to estimate the distribution of cigarette use rates among SMVs in all 50 states in the United States. Significant state-level variation was observed in cigarette use rates between SMV and civilian populations. Resources and interventions directed at cigarette smoking cessation should, therefore, consider military status and geography when recruiting participants. Future studies should consider estimating cigarette use rates among SMVs at finer geographical resolutions, similar to the way in which mental distress rates were estimated at the county level in the McDaniel et al. ${ }^{10}$ study of Kentucky SMVs. Local-level estimates could be used to develop unique interventions tailored specifically for a small geographical location.

\section{REFERENCES}

1. Odani S, Agaku IT, Graffunder CM, Tynan MA, Armour BS. Tobacco product use among military veternas United States, 2010-2015. MMWR Morb Mortal Wkly Rep. 2018;67(1):7-12. doi:10.15585/mmwr.mm6701a2

2. Talcott GW, Ebbert JO, Klesges RC, et al. Tobacco research in the military: Reflections on 20 years of research in the United States Air Force. Mil Med. 2015;8(1):848-850. doi:10.7205/milmed-d-14-00501

3. Centers for Disease Control and Prevention. 2017 BRFSS survey data and documentation. https://www.cdc.gov/ brfss/annual_data/annual_2017.html. Accessed February $10,2019$.

4. Centers for Disease Control and Prevention. The behavioral risk factor surveillance system: Complex sampling weights and preparing 2017 BRFSS module data for analysis. https://www.cdc.gov/brfss/annual_ 
data/2017/pdf/Complex-Smple-Weights-Prep-ModuleData-Analysis-2017-508.pdf. Accessed February 10, 2019.

5. Centers for Disease Control and Prevention. Comparability of data: BRFSS 2011. https://www.cdc.gov/brfss/annual_ data/2011/pdf/compare_11_20121212.pdf. Accessed February 19, 2019.

6. Jahnke SA, Hoffman KM, Haddock CK, Long MAD, Williams LN, Lando HA, Poston WSC. Military tobacco policies: The good, the bad, and the ugly. Mil Med. 2011;176(12):13821387. doi:10.7205/milmed-d-11-00164

7. North American Quitline Consortium. NAQC quitline map. http://map.naquitline.org/. Accessed June 13, 2019.

8. Matthieu MM, Lawrence KA, Robertson-Blackmore E. The impact of a civic service program on biopsychosocial outcomes of post 9/11 U.S. military veterans. Psychiatry Res. 2017;248:111-116. doi:10.1016/j.psychres.2016.12.028

9. McDaniel JT, Thomas KH, Angel CM, et al. Regional differences in BMI, obesity, and exercise frequency in a large veteran service organization: A secondary analysis of new veteran member surveys from Team Red, White, and Blue. Prev Med Rep. 2018;12:116-121. doi:10.1016/j.pmedr.2018.09.001

10. McDaniel JT, Albright DL, Rados R, McDermott R, Goelz H, Juul K. Military-civilian residential segregation and military member psychological distress in Kentucky counties. GeoJournal. doi:10.1007/s10708-019-10053-x
CONFLICTS OF INTEREST

The authors have completed and submitted the ICMJE Form for Disclosure of Potential Conflicts of Interest and none was reported.

FUNDING

There was no source of funding for this research.

AUTHORS' CONTRIBUTIONS

The authors contributed equally to the development of this manuscript.

PROVENANCE AND PEER REVIEW

Not commissioned; externally peer reviewed. 